Tropical Journal of Pharmaceutical Research January 2017; 16 (1): 67-74

ISSN: $1596-5996$ (print); 1596-9827 (electronic)

(c) Pharmacotherapy Group, Faculty of Pharmacy, University of Benin, Benin City, 300001 Nigeria.

All rights reserved.

Available online at http://www.tjpr.org

Original Research Article

http://dx.doi.org/10.4314/tjpr.v16i1.9

\title{
Molecular docking and in silico ADMET studies of silibinin and glycyrrhetic acid anti-inflammatory activity
}

\author{
Arif Malik ${ }^{1}$, Abdul Manan ${ }^{1}$ and Muhammad Usman Mirza ${ }^{2,3 *}$ \\ ${ }^{1}$ Institute of Molecular Biology and Biotechnology, ${ }^{2}$ Centre for Research in Molecular Medicine, The University of Lahore, \\ Lahore, Pakistan, ${ }^{3}$ Department of Pharmaceutical and Pharmacological Sciences, Rega Institute for Medical Research, \\ Medicinal Chemistry, University of Leuven, Leuven B-3000, Belgium
}

*For correspondence: Email: usmanmirzapk@yahoo.com, muhammad.usman@imbb.uol.edu.pk

Received: 21 July 2016

Revised accepted: 10 December 2016

\begin{abstract}
Purpose:To use in silico docking analysis and ADMET prediction of silibinin and glycyrrhetic acid to determine their pharmacokinetic and pharmacodynamic properties as therapeutic molecules against inflammatory disorders.

Methods: The study utilized plant-derived compounds with known anti-inflammatory activity. Three important enzymes, including COX-2, 5 $\beta$-reductase and phospholipase A2, that are involved in the mediation of inflammatory processes, were chosen as protein targets for the ligands (silibinin and glycyrrhetic acid). Q-Site Finder and admetSAR were employed for active site prediction and ADMET profile, respectively. Furthermore, protein-ligand complexes were visually inspected by LigPlot and Chimera.

Results: Post-docking analysis confirmed strong interaction of silibinin and glycyrrhetic acid with their respective targets. ADMET profiles for both compounds were very promising. Both ligands (silibinin and glycyrrhetic acid) showed strong binding energy for all three target proteins (-7.5 to $-10.9 \mathrm{kcal} / \mathrm{mol})$. Moreover, Asp347, Gln350, Gly354, Gln192, His351, Ser579 and Phe580 were the common interacting residues in the target proteins for both ligands.

Conclusion:Glycyrrhetic acid possesses superior ADMET profile to silibinin. Hydrophobic interactions between the two ligands (glycyrrhetinic acid and silibinin) and the three target proteins (COX-2, phospholipase $A 2$ and $5 \beta$-reductase) are significant.
\end{abstract}

Keywords:Silibinin, Glycyrrhetic acid, ADMET, Docking studies, Phospholipase A2, COX-2, 5 $\beta$ Reductase

Tropical Journal of Pharmaceutical Research is indexedby Science Citation Index (SciSearch), Scopus, International Pharmaceutical Abstract, Chemical Abstracts, Embase, Index Copernicus, EBSCO, African Index Medicus, JournalSeek, Journal Citation Reports/Science Edition, Directory of Open Access Journals (DOAJ), African Journal Online, Bioline International, Open-J-Gate and Pharmacy Abstracts

\section{INTRODUCTION}

Xenobiotics and toxins injure the liver and can result in substantial hepatic pathology. The liver metabolizes and excretes drugs and xenobiotics. All drugs have some side effects, and many affect hepatocytes including cisplatin, tegafur, cyclophosphamide (anti-cancer drugs), nefazodone (an antidepressant), and some diabetes medications [1]. Hepatocytes are also responsible for the excretion of drugs from animals [1]. Drug overdose, toxins, chemotherapeutic agents like acetamide, and a hepatotoxic agent, carbon tetrachloride $\left(\mathrm{CCl}_{4}\right)$ can damage hepatocytes and lead to liver inflammation (hepatitis) and cirrhosis [2]. Plants and their extracts have been usedto treat human diseases since ancient time. Among these, some plants have been reported to have additional medicinal value and beneficial characteristics including anti-inflammatory, immune-modulatory and anti-viral actions on hepatoprotective 
properties [3-5]. The secondary metabolites of herbal treatments have become more prominent for the treatment of liver disease, with evidencebased outcomes being established through promising clinical trials and validation.

Silybummarianum, commonly known as milk thistle, produces seeds that have medicinal value when ripe [6,7]. Silymarin (SLN), an important secondary metabolite of Silybummarianum, consists of a complex mixture of four isomers (flavonolignans): silybin, isosilybin, silydianin, and silychristin. SLN has anti-inflammatory, anti-lipid, immuno-modulatory, anti-oxidative, and hepatocyte-regenerating actions. However, it is not thought to be anti-viral $[1,2]$. Glycyrrhizaglabra is a leguminous plant belonging to the Leguminosae family [8]. The root extract of Glycyrrhizaglabra contains various chemical compounds of medicinal value including saponin, triterpines, flavonoids, and other chemicals like sugars, coumarins, amino acids, choline, and tannins $[4,9,10]$.Moreover, in Japan, glycyrrhetic acid GLN is used for the management of chronic hepatitis C [11]. Glycyrrhizin metabolism is important because its metabolites inhibit the production of aldosterone and suppress 5- $\beta$ reductase commonly called hepatic pseudoaldosterone syndrome. There is an inhibition of phospholipase A2 activity which is important in various inflammatory processes. Glycyrrhizin has the ability to interfere with cyclooxygenase and prostaglandin production involved in the progression of inflammatory mechanisms in biological system [18].

In the current study, molecular docking strategy was performed to find out their respective binding energies along with the number of hydrogen bonds and other hydrophobic interactions. The study was further validated by the use of in silico ADMET prediction of both compounds (silibinin and glycyrrhetic acid) in order to check their pharmacokinetics and pharmacodynamics properties. These two compounds have already being tested as potent therapeutic compounds in various experimental trials. The compounds are being viewed as potent therapeutic molecules in the management of inflammatory disorders.

\section{EXPERIMENTAL}

Target proteins were docked with silibinin and glycyrrhetic acid using AutoDock 4.2 and binding energies were calculated.

\section{Structure retrieval}

The three dimensional crystal structures of the three target proteins were retrieved from the
Protein Data Bank. Cyclooxygenase-2 (6COX) [12], 5-beta-reductase (3BV7) [13], and phospholipase A2 (2B03) [14] were taken as targets. The ligand molecules, glycyrrhetic acid (GLN) and silibinin (SLB) were retrieved from PubChem (https://pubchem.ncbi.nlm.nih.gov) and were refined using ACD ChemSketch (http://www.acdlabs.com/resources/freeware), a tool that offers functionalities such as structure refining, optimization, etc.

\section{Active site prediction}

The active sites of all the three target proteins were identified using Q-SiteFinder [15]. QSiteFinder works by binding hydrophobic probes to the protein. It then finds the clusters of probes with most favorable binding region based on energy values. It ranks these clusters according to the sum of total binding energies for individual clusters in the order of likelihood of being a binding site.

Various pharmacodynamic as well as pharmacokinetic parameters were considered including human intestinal absorption (HIA), Caco-2 permeability, aqueous solubility, bloodbrain barrier penetration, renal organic cation transportation, cytochrome P (CYP) inhibitory promiscuity, cytochrome $\mathrm{P}_{450}$ inhibition, AMES toxicity, fish toxicity, rat acute toxicity, Tetrahymenapyriformis toxicity, human ether-ago-go-related genes inhibition, mutagenic, tumorigenic and reproductive risks (Table 1).

\section{Docking studies}

Target proteins were docked with silibinin and glycyrrhetic acid using AutoDock 4.2. The free energy of binding between the ingredients of ligands and proteins were calculated. AutoDock 4.2 uses charge-based desolvation force fields and well defined improved models of the unbound state. Docking analysis attempts to bind the ligand into the obtained binding sites of the target protein and produces the best docked conformations with minimal energy, as the output. Semi-flexible docking protocol was applied, wherein the target proteins were kept rigid while the phytochemical ligands were kept flexible for being docked upon. A $5 \mathrm{~A}^{\circ}$ grid was built surrounding the binding pocket. Grid maps dimensions were set as $60 \times 60 \times 60$ points with spacing of $0.375 \mathrm{~A}^{\circ}$ to yield the receptor model that included atoms within $0.5 \mathrm{~A}^{\circ}$ of the grid center. All the other parameters were kept at default and Lamarckian Genetic Algorithm (LGA) was chosen to predict the best conformers. The protein - ligand complexes were viewed by LigPlot viewer (http://www.ebi.ac.uk/thornton- 
srv/software/LIGPLOT) and (http://www.cgl.ucsf.edu/chimera).

\section{Drug-likeness analysis}

Chosen compounds were subjected to further selection on the basis of Lipinski's rule of five (Ro5) [16]. Lipinski's screening was performed using Molinspiration server (http://www.molins piration.com/cgi-bin/properties) and physicochemical properties of ligands were calculated. Drug scores were calculated using ORISIS property explorer prog/peo).

\section{Absorption, distribution, metabolism, elimination and toxicity (ADMET) studies}

The molecular structure of both ligands were submitted to ADMET-SAR server (http://Immd. ecust.edu.cn:8000) to examine their drug likeliness and different pharmacokinetic and pharmacodynamic parameters including bloodbrain barrier penetration, human intestinal absorption, Caco-2 permeability, cytochrome P450 solubility, cytochrome P (CYP) inhibitory promiscuity, renal organic cation transportation, human ether-a-go-go related genes inhibition, rat acute toxicity, fish toxicity, Tetrahymena pyriformis toxicity and Ames toxicity.

\section{RESULTS}

Both ligands (silibinin and glycyrrhetic acid) have shown strong binding energy with all three target proteins $(-7.5$ to $-10.9 \mathrm{Kcal} / \mathrm{mol})$. The said compounds followed the Lipinski's rule in Table 2 of five without any violation with respect to molecular weight $(\leq 500 \mathrm{KDa})$, an octanol-water partition coefficient $(\log P \leq 5)$, molecular refractivity $(40-130)$, number of $\mathrm{H}$-bond acceptors $(\leq 10)$ and number of $\mathrm{H}$-bond donors $(\leq 5)$. Lipinski's rule of five analyzes various physiochemical properties [16]. These includes Log $P$ anoctanol water partition coefficient which should be greater than or equal to 5 , number of $\mathrm{H}$-bonds donors and acceptor $\leq 5$ and $\leq 10$ respectively, molecular weight of greater than 500 and a molecular refractivity in the range of 40-130. The Lipinski's screening is an essential filter that determines if a compound is suitable for drug designing. Upon docking, both silibinin and glycyrrheticacid (Figure 1) formed at least one hydrogen bonds with all three target proteins. Docking with cyclooxygenase-2 (6COX) hydrogen bonds formation were observed with Phe580 residue having bond length of $2.84 \AA$ (silibinin) and $3.09 \AA$ (glycyrrhetic acid) as shown in Figure 2. Additionally, Asp347, Gln350, Gly354, Gln192, His351, Ser579, Phe580 were found to be common interacting residues in the target proteins for both ligands.

Significant numbers of hydrophobic interactions were observed between the two ligands and all three target proteins. When docked with 5-betareductase (3BV7) Pro221, Lys273, Ile271, Gly24, Tyr26, Trp230, Val309, Ser225, Ser220 residues interacted with silibinin and glycyrrhetic acid in addition to a few other residues. Similarly, Phospholipase A2 (2B03) docking analysis revealed Leu41, Tyr111, Leu19, Phe106, Ile9, Met20, Asn23, Leu31, Gly30, Leu2 and Tyr69 as common amino acid residues responsible for scoring a high binding energy of $-8.8 \mathrm{kcal} / \mathrm{mol}$ and $-10.9 \mathrm{kcal} / \mathrm{mol}$ for silibinin and glycyrrhetic acid respectively (Figure 3 ). All docking results are summarized in Table 3.<smiles>COc1cc([C@H]2Oc3cc([C@@H]4Oc5cc(O)cc(O)c5C(=O)[C@H]4O)ccc3O[C@@H]2CO)ccc1O</smiles>

(2R,3R)-3,5,7-trihydroxy-2-((2R,3R)-3-(4-hydroxy-3-methoxyphenyl)-2-(hydroxymethyl)-2,3dihydrobenzo $[b][1,4]$ dioxin-6-yl)chroman-4-one

Silibinin 


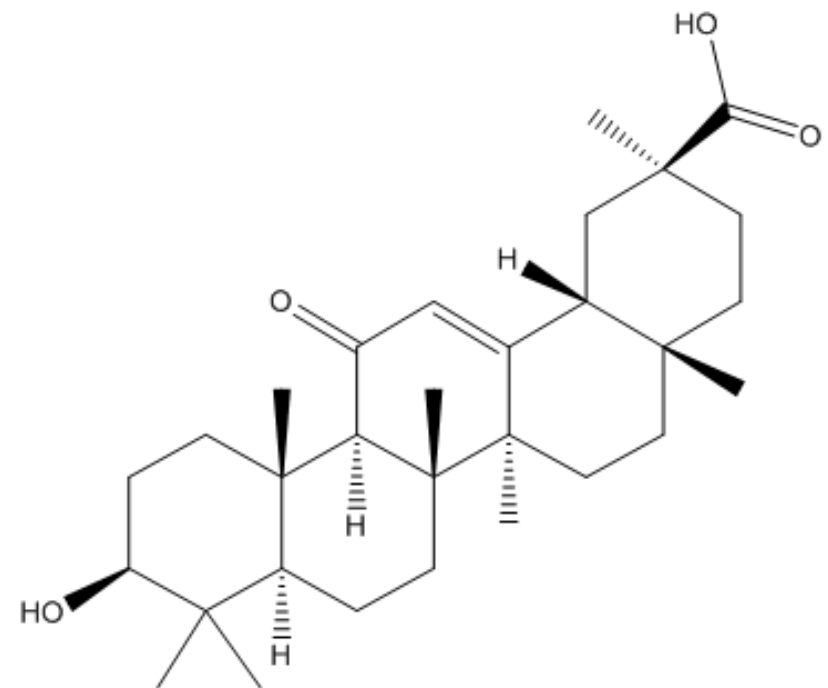

( $2 S, 4 \mathrm{a} S, 6 \mathrm{a} S, 6 \mathrm{~b} R, 8 \mathrm{a} R, 10 S, 12 \mathrm{a} S, 12 \mathrm{~b} R, 14 \mathrm{~b} R)$-10-hydroxy-2,4a,6a,6b,9,9,12a-heptamethyl-13-oxo-

$1,2,3,4,4 \mathrm{a}, 5,6,6 \mathrm{a}, 6 \mathrm{~b}, 7,8,8 \mathrm{a}, 9,10,11,12,12 \mathrm{a}, 12 \mathrm{~b}, 13,14 \mathrm{~b}$-icosahydropicene-2-carboxylic acid

Glycyrrhetic acid

Figure1: Molecular structures of silibinin and glycyrrhetic acid
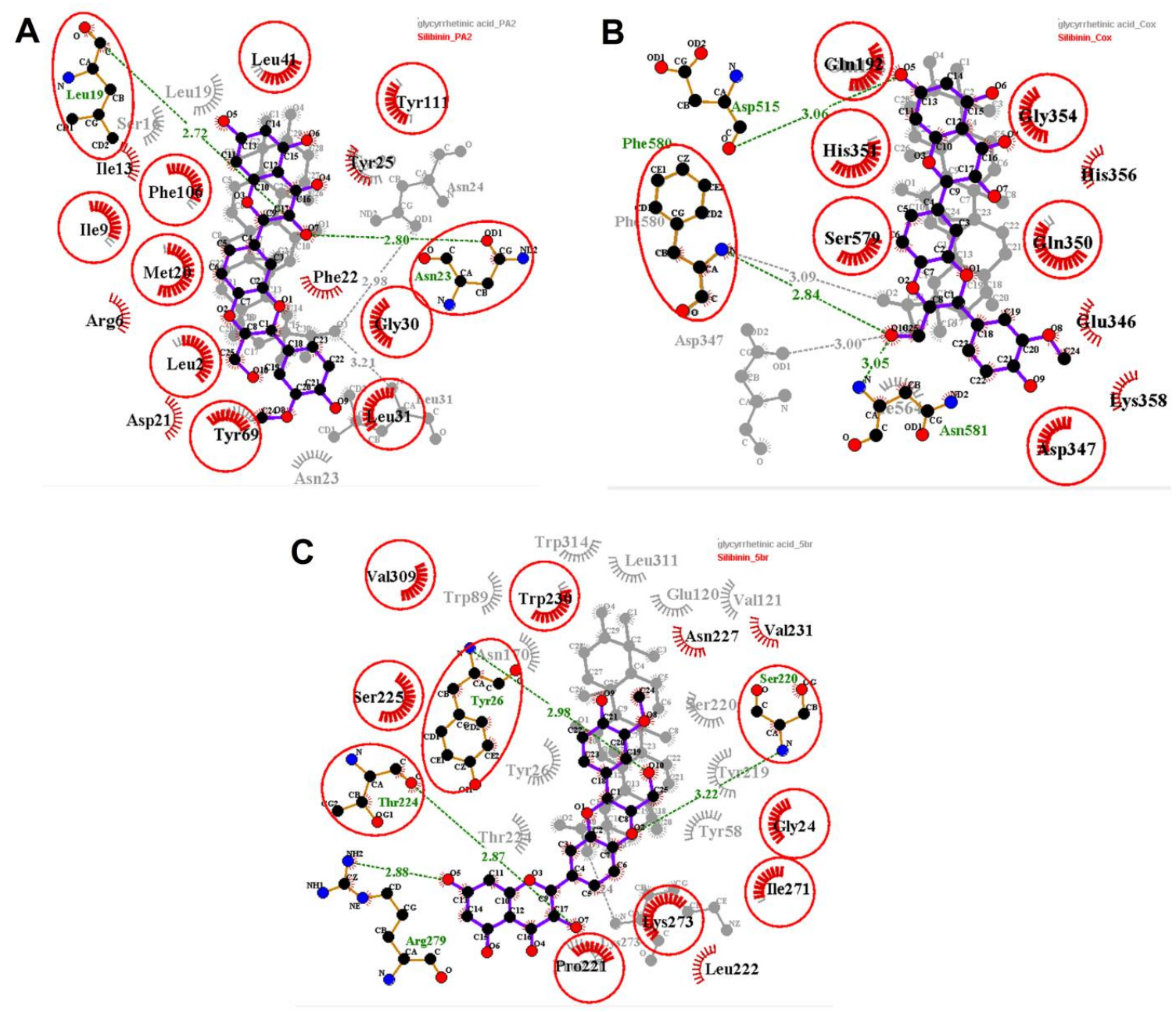

Figure2: Schematic diagram of binding modes of glycyrrhetic acid (in grey) and silibinin (in purple) with respective target proteins: cyclooxygenase-2 (A), 5-Beta reductase (B) and phospholipase A2 (C). The conserved residues of each target protein are shown in red circle for both ligands. This figure was produced by using LigPlot 

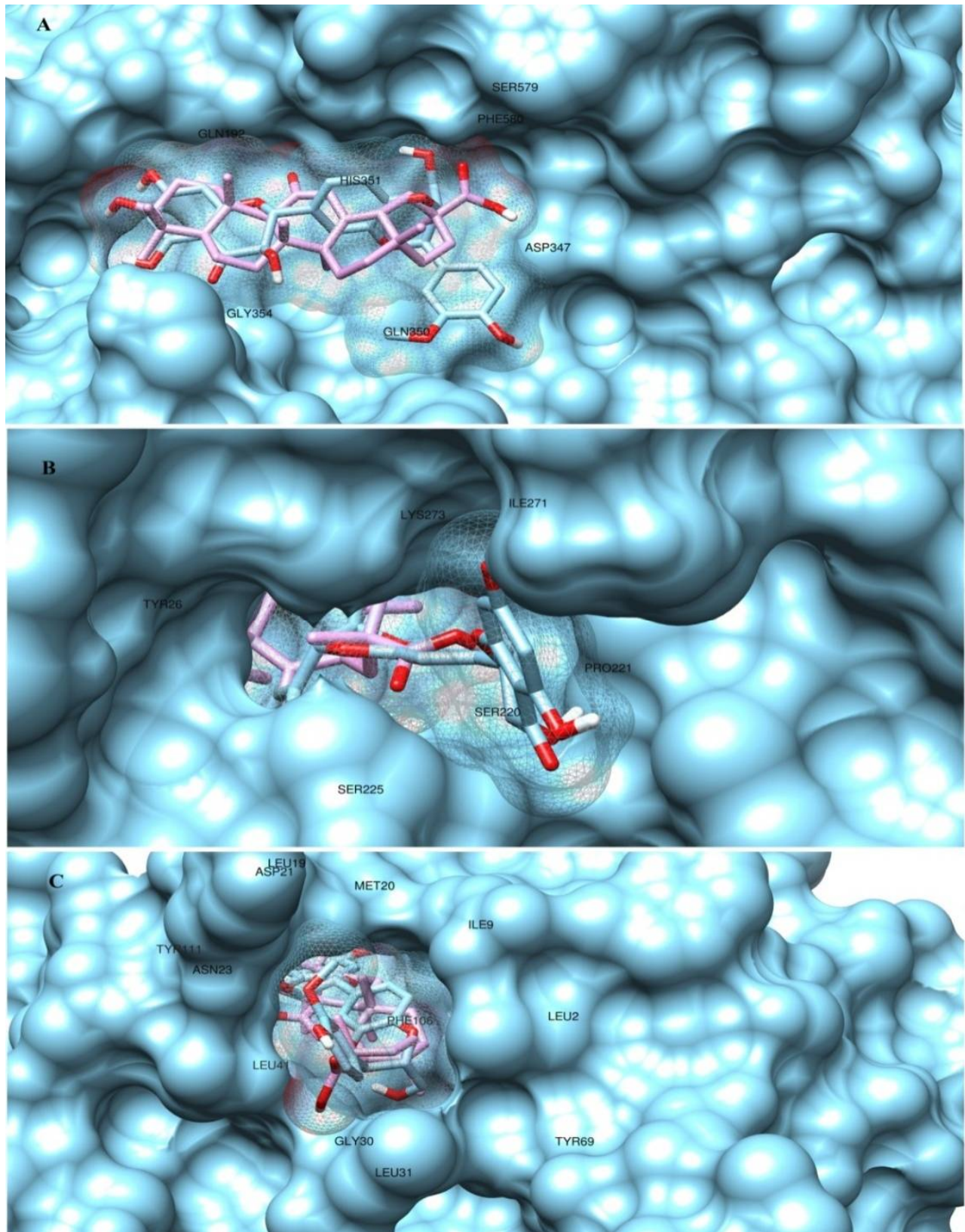

Figure 3: Molecular representation of target proteins with docked compounds. Conformation of glycyrrhetic acid (in pink) and silibinin (in blue) shown by sticks inside the binding pocket of cyclooxygenase-2 (A), 5-Beta reductase (B) and phospholipase A2 (C) shown in molecular surface representation in sky blue color

Table 2: Comparison of drug-likeness properties of silibinin and glycyrrhetic acid

\begin{tabular}{lcc}
\hline Drug-likeness properties & Silibinin & Glycyrrhetic acid \\
\hline Molecular weight & 482.4345 & 470.6825 \\
LogP & 2.3627 & -5.36 \\
LogS & -3.41 & -5.78 \\
H-bond acceptors & 10 & 4 \\
H-bond donors & 5 & 2 \\
Rotatable bonds & 4 & 1 \\
Heavy atoms & 35 & 34 \\
Hydrogen atoms & 22 & 46 \\
PSA & 155.14 & 74.6 \\
RO5 violation & 0 & 0 \\
Refractivity & 120.5501 & 136.8536 \\
Drug-Likeness score & 1.64 & -2.36 \\
Drug score & 0.64 & 0.2 \\
\hline
\end{tabular}


Table3: Comparison of binding energies $(\Delta \mathrm{G})$, interacting residues, $\mathrm{H}$-bonds and hydrophobic interactions

\begin{tabular}{|c|c|c|c|}
\hline Target protein (PDB code) & Docking results & Silibinin & Glycyrrhetic acid \\
\hline Cyclooxygenase-2 (6COX) & $\begin{array}{l}\text { H-bonds } \\
\text { Hydrophobic } \\
\text { Interactions }\end{array}$ & 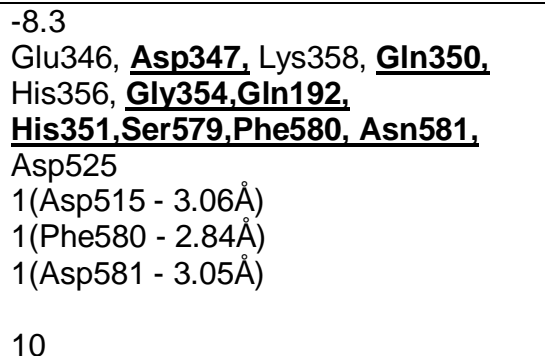 & 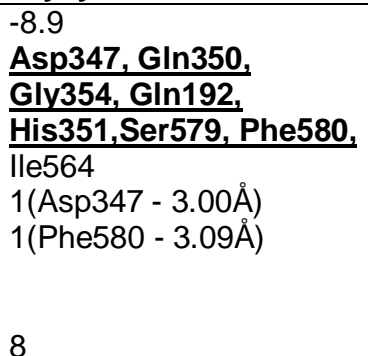 \\
\hline \multirow[t]{4}{*}{ 5-Beta-reductase (3BV7) } & Binding energy $\Delta G$ & -10.1 & -7.5 \\
\hline & Interacting residues & $\begin{array}{l}\text { Pro221, Leu222, } \\
\text { Lys273,Ile271,Gly24,Ser220,Val231, } \\
\text { Asn227, Tyr26, Trp230, } \\
\text { Val309, Ser225, Arg279, Thr224 }\end{array}$ & $\begin{array}{l}\text { Pro221, Lys273, lle271, } \\
\text { Tyr58, Tyr219, Gly24, } \\
\text { Ser220, Glu120, Val121, } \\
\text { Trp314, Trp89, Leu311, } \\
\text { Asn170,Trp230, Val309, } \\
\text { Ser225, Tyr26 }\end{array}$ \\
\hline & H-Bonds & $\begin{array}{l}1(\text { Tyr26 }-2.98 \AA) \\
1(\text { Arg279 }-2.88 \AA) \\
1(\text { Thr224 }-2.87 \AA) \\
1(\text { Ser220 }-3.22 \AA)\end{array}$ & 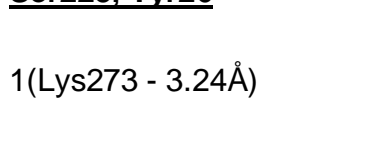 \\
\hline & $\begin{array}{l}\text { Hydrophobic } \\
\text { interactions }\end{array}$ & $\begin{array}{r}11 \\
-88\end{array}$ & $\begin{array}{r}16 \\
-109\end{array}$ \\
\hline \multirow[t]{3}{*}{ Phospholipase A2 (2B03) } & $\begin{array}{l}\text { Binding energy } \Delta G \\
\text { Interacting residues }\end{array}$ & $\begin{array}{l}\text { Leu2,Arg6,Tyr69, Asp21, Asn23, }^{-8.8} \\
\text { Leu31, Gly30,Phe22, Tyr25,Leu41, } \\
\text { Tyr111, Leu19,Ile13,Phe106, Ile9, } \\
\text { Met20 }\end{array}$ & $\begin{array}{l}\text { Leu2,Tyr69, } \\
\text { Asp21, Asn23, Leu31, } \\
\text { Gly30, Tyr25, Asn24, } \\
\text { Cys29, Leu41, Tyr111, } \\
\text { Leu19,Phe106, lle9, } \\
\text { Met20 }\end{array}$ \\
\hline & H-bonds & $\begin{array}{l}1(\text { Leu19 }-2.72 \AA) \\
1(\text { Asn23 }-2.80 \AA)\end{array}$ & $\begin{array}{l}1 \text { (Leu31 }-3.21 \AA ̊) \\
1 \text { (Asn24 - } 2.98 \AA)\end{array}$ \\
\hline & $\begin{array}{l}\text { Hydrophobic } \\
\text { interactions }\end{array}$ & 14 & 13 \\
\hline
\end{tabular}

\section{DISCUSSION}

Plants secondary metabolites have medicinal values and show therapeutic potential like antiviral, anti-inflammatory and immune-modulatory effects. The interest of investigators has been moved towards herbs because they are used as functional foods and an important source for the preparation of drugs. Hence, herbal medicines have been used worldwide for the treatment of various diseases. Inflammation is protective response involving molecular mediators, immune cells and blood vessels. Phytochemicals like silymarin and glycyrrhizin in suitable combinations are used as drugs for patients with liver disorders as they possess hepatoprotective property against inflammation [11,17]. Docking methodology facilitates structure-based virtual database screening with the ability to achieve a cost effective and quick estimation of the affinity and binding mode of a ligand for drug target. In this study, glycyrrhetic acid and silibinin have been shown to possess significant antiinflammatory activity from ADMET prediction. Moreover, the difference between binding energies can be observed in Table 3. Both the ligands occupied the same location in the protein targets and shared common amino acid residues for the inhibition of proteins' action in inflammation.

Poor pharmacokinetics and toxicity in the biological system lead to failure in drug development. With the help of ADMET profile during the process of drug discovery one can removeincompatible compounds as well as exhibit significant role in reducing cost and efforts [19]. For a drug to be approved for use, tedious toxicological analysis are performed to ensure its safety upon ingestion. In silico ADMET analysis is a quick approach to find if a compound has acceptable pharmacokinetics and pharmacodynamics property. The toxicity risks and bioavailability of silibinin and glycyrrhetic acid were predicted based on their ADMET profile [20]. Further analysis exhibit CYP inhibitory promiscuity as silibinin inhibit two cytochromes including CYP450-2C9 and CYP450-3A4. 
Table1: ADMET-predicted features of glycyrrhetic acid and silibinin

\begin{tabular}{lcc}
\hline Property & Glycyrrhiticacid & Silibinin \\
\hline Blood-brain barrier & BBB+ & BBB- \\
Human intestinal absorption & HIA+ & HIA+ \\
Caco-2 permeability & Caco2+ & Caco+ \\
P-glycoprotein substrate & Substrate & Substrate \\
Renal organic cation transporter & Non-inhibitor & Non-inhibitor \\
CYP450 2C9 substrate & Non-substrate & Non-substrate \\
CYP450 2D6 substrate & Non-substrate & Non-substrate \\
CYP450 3A4 substrate & Substrate & Non-substrate \\
CYP450 1A2 inhibitor & Non-inhibitor & Non-inhibitor \\
CYP450 2C9 inhibitor & Non-inhibitor & Inhibitor \\
CYP450 2D6 inhibitor & Non-inhibitor & Non-inhibitor \\
CYP450 2C19 inhibitor & Non-inhibitor & Non-inhibitor \\
CYP450 3A4 inhibitor & Non-inhibitor & Inhibitor \\
CYP inhibitory promiscuity & Low CYP inhibitory & High CYP inhibitory \\
& promiscuity & promiscuity \\
AMES toxicity & Non-AMES toxic & Non-AMES toxic \\
Carcinogens & Non-carcinogens & Non-carcinogens \\
Fish ioxicity & High FHMT & High FHMT \\
Tetrahymenapyriformis toxicity & High TPT & High TPT \\
Honey bee ioxicity & High HBT & High HBT \\
& Not readily & Not readily \\
Biodegradation & biodegradable & biodegradable \\
Acute oral toxicity & III & III \\
Carcinogenicity (three-class) & Not-required & Not-required \\
\hline
\end{tabular}

Depending upon the acute oral toxicity (ADMET prediction profile), compounds are categorized into four groups. Category I contains compounds with $L D_{50}$ values less than or equal to $50 \mathrm{mg} / \mathrm{kg}$. Category II contains compounds with $\mathrm{LD}_{50}$ values greater than $50 \mathrm{mg} / \mathrm{kg}$ but less than $500 \mathrm{mg} / \mathrm{kg}$. Category III includes compounds with $\mathrm{LD}_{50}$ values greater than $500 \mathrm{mg} / \mathrm{kg}$ but less than $5000 \mathrm{mg} / \mathrm{kg}$. Category IV consisted of compounds with $\mathrm{LD}_{50}$ values greater than 5000 $\mathrm{mg} / \mathrm{kg}$.

The role of cytochrome $\mathrm{P}_{450}$ enzymes is very important as they are responsible for the metabolism of drug in biological system and its clearance from the body. Inhibition of any isoform of CYP leads to the malfunctioning of drug metabolism and elevation of toxicity [21].

After ADMET analysis of compounds under study it was observed that glycyrrhetic acid possesses better ADMET profile when compared to silibinin, because it can cross blood-brain barrier but not the silibinin, it is non-inhibitor for all CYPinhibitors while silibinin is inhibitor for two CYPs like CYP-2C9 and CYP-3A4. Moreover, glycyrrhetic acid presented low CYP inhibitory promiscuity as compared to silibinin (Table 1). Both compounds were non carcinogenic and showed no AMES toxicity. Both compounds were found to be fit for drug development.

\section{CONCLUSION}

Glycyrrhetic acid possesses better ADMET profile than silibinin. Furthermore, hydrophobic interactions were significantly high between two ligands (glycyrrhetic acid and silibinin) and three target proteins (COX-2, phospholipase A2 and $5 \beta$-reductase). Ligand-receptor complex showed that strong hydrogen bonding and van der Waals interactions were formed indicating that these two phytochemicals are suitable options as antiinflammatory agents as well as can be considered safe for development into a commercial drug when compared to other drugs in terms of their relatively fewer side-effects.

\section{DECLARATIONS}

\section{Acknowledgement}

The authors are very thankful to DrMehmood Husain Qazi for his support during this study.

\section{Conflict of Interest}

No conflict of interest associated with this work. 


\section{Contribution of Authors}

The authors declare that this work was done by the authors named in this article and all liabilities pertaining to claims relating to the content of this article will be borne by them.

\section{Open Access}

This is an Open Access article that uses a funding model which does not charge readers or their institutions for access and distributed under the terms of the Creative Commons Attribution License (http://creativecommons.org/licenses/by 14.0) and the Budapest Open Access Initiative (http://www.budapestopenaccessinitiative.org/rea d), which permit unrestricted use, distribution, and reproduction in any medium, provided the original work is properly credited.

\section{REFERENCES}

1. Pradhan SC, Girish C. Hepatoprotective herbal drug, silymarin from experimental pharmacology to clinical medicine. Indian J Med Res 2006; 124:491-504.

2. Rasool M, Iqbal J, Malik A et al. Hepatoprotective Effects of Silybummarianum (Silymarin) and Glycyrrhizaglabra (Glycyrrhizin) in Combination: A Possible Synergy. Evidence-Based ComplemAltern Med 2014; 2014: 1-9

3. Asghar Z, Masood Z. Evaluation of antioxidant properties of silymarin and its potential to inhibit peroxyl radicals in vitro. Pak J Pharm Sci 2008; 21(3): 249-254.

4. Fukai T, Marumo A, Kaitou K, Kanda T, Terada $S$, Nomura T. Anti-Helicobacter pylori lavonoids from licorice extract. Life Sci 2002; 71(12): 1449-1463.

5. Kim SH, Cheon HJ, Yun N, Oh ST, Shin E, Shim KS, Lee $S M$. Protective effect of amixture of Aloe vera and Silybummarianum against carbon tetrachloride-induced acute hepatotoxicity and liver fibrosis. I Pharm Sci 2009; 109(1): 119-127.

6. Francis $R$. The Wild Flower Key. Frederick Warne \& Co. 1981; pp 388-389.

7. Rameshwar J, Anand K. Protective effect of L-ornithine$L$-aspartate and silymarin on chemically induced kidney toxicity and thyroid dysfunction in mice. EXCLI J 2008; 7: 139-150.

8. Fenwick G, Lutomski J, Nieman C. Glycyrrhizaglabra L. (Liquorice): Composition, uses and analysis. Food Chem 1990; 38(2): 119-143.
9. Snow J. GlycyrrhizaglabraMonograph. J Bot Med 1996; 1(3):9-14.

10. Arystanova T, Irismetov TM, Sophekova $A$. Chromatographic determination of glycyrrhizinic acid in Glycyrrhizaglabra preparation. Chem Nat Com 2001; 37: 89-91.

11. Okuno M, Kojima S, Moriwaki H. Chemoprevention of hepatocellular carcinoma: concept, progress and perspectives. J GastroenterolHepatol 2001; 16(12): 3291335.

12. Kurumbail RG, Stevens AM, Gierse JK, McDonald JJ, Stegeman RA, Pak JY, Gildehaus D, Miyashiro JM, Penning TD et al. Structural basis for selective inhibition of cyclooxygenase-2 by anti-inflammatory agents. Nature 1996; 384: 644-648.

13. Di Costanzo L, Drury JE, Penning TM, Christianson DW. Crystal Structure of Human Liver $\Delta 4-3$-Ketosteroid $5 \beta$ Reductase (Akr1d1) and Implications for Substrate Binding and Catalysis. J BiolChem 2008; 283(24): 16830-16839.

14. Pan YH, Bahnson BJ. Structural Basis for Bile Salt Inhibition of Pancreatic Phospholipase A2. J MolBiol 2007; 369(2): 439-450.

15. Laurie AT, Jackson RM. Q-SiteFinder: an energy-based method for the prediction of protein-ligand binding sites. Bioinformatics 2005; 21(9): 1908-1916.

16. Lipinski CA, Lombardo F, Dominy BW, Feeney PJ. Experimental and computational approaches to estimate solubility and permeability in drug discovery and development settings. Adv Drug Deliv Rev 2001; 46(13): 3-26.

17. Chaudhary GD, Kamboj P, Singh I, Kalia AN. Herbs as liver saver. Ind J Nat Prod Res 2010; 1(4): 397-408.

18. Libby $P$. Inflammatory mechanisms: the molecular basis of inflammation and disease. Nutr Rev 2007; 65: 140146.

19. Mirza MU, Ghori NU, Ikram N, Adil AR, Manzoor S. Pharmacoinformatics approach for investigation of alternative potential hepatitis $C$ virus nonstructural protein 5B inhibitors. Drug Des DevTher 2015; 9: 18251941.

20. Mirza MU, Mirza AH, Ghori NU, Ferdous S. Glycyrrhetinic acid and E. resveratroloside act as potential plant derived compounds against dopamine receptor D3 for Parkinson's disease: a pharmacoinformatics study. Drug Des DevTher 2014; 9: 187-198.

21. Lynch T, Price A. The effect of cytochrome $P 450$ metabolism on drug response, interactions, and adverse effects. Am Fam Physician 2007; 76(3): 391-396. 